\title{
FORMAÇÃO CONTINUADA DE PROFESSORES DAS SÉRIES INICIAIS DO ENSINO FUNDAMENTAL DA REDE MUNICIPAL DE MACAPÁ-AP
}

\author{
Elivaldo Serrão Custódiol \\ Paulo Ronaldo Gomes Cruz ${ }^{2}$
}

\section{RESUMO}

A presente pesquisa teve como objetivo analisar a oferta de formação continuada a professores da rede municipal de ensino de Macapá, bem como av eriguar a real aplicabilidade de metodologias e recursos decorrentes de Programas e Projetos, à realidade de sala de aula. Para isso, utilizou-se a pesquisa exploratória de campo, a partir da qual se ouviu, primeiramente, coordenadores de formações, que apresentaram documentos e registros confirmando a oferta de formação continuada aos professores da rede. Em seguida, foi aplicado um questionário contendo questões de múltiplas escolhas e outras dissertativas, aos docentes da rede municipal, que se encontravam em formação pelo Pacto Nacional pela Alfabetização na Idade Certa - PNAIC. Os resultados confirmaram a hipótese de que a falta da formação continuada interfere na prática profissional docente em sala de aula; que reconhecidamente há um índice muito alto de desistência dos profissionais nas formações; que os participantes da pesquisa, na maioria, pertencem ao contrato administrativo da prefeitura, sendo que os professores que participam das formações já conseguem visualizar resultados positivos principalmente em relação à leitura, que eles utilizam os recursos pedagógicos e metodologias na prática em sala de aula.

Palavras-chave: Formação continuada. Educação pública. Macapá-AP.

\section{CONTINUING EDUCATION OF PRIMARY SCHOOL TEACHERS FROM THE}

\section{MUNICIPAL SCHOOL NETWORK IN MACAPÁ-AP}

\begin{abstract}
The research reported in this paper aimed to analyze the offer of continuing education to teachers from the municipal school network in Macapá, state of Amapá, and to investigate the real applicability of methodologies and resources

1 Pós-Doutor em Educação pela Universidade Federal do Amapá (UNIFAP). Doutor em Teologia pela Faculdades EST, em São Leopoldo/RS. Professor permanente no Mestrado em Educação (PPGED/UNIFAP). ORCID iD: http://orcid.org/0000-0002-2947-5347. E-mail: elivaldo.pa@hotmail.com. E-mail: elivaldo.pa@hotmail.com

2 Graduado em Letras pela Universidade Vale do Acaraú. Professor da rede pública de ensino do município de Afuá/Pará/Brasil. ORCID iD: https://orcid.org/0000-0001-6044-5755. Email: paulocni@hotmail.com. E-mail: paulocni@hotmail.com
\end{abstract}


derived from programs and projects to the reality of classrooms in the municipality. For that purpose, exploratory field research was used in two stages. In the first stage, teacher education coordinators were interviewed - these coordinators presented documents and records that confirmed the offer of continuing education to the teachers from the network. In the second stage, a questionnaire containing multiplechoice and essay questions was administered to the teachers of the municipal school network who were undertaking continuing professional development through the National Pact for Literacy in the Right Age - PNAIC. The results, on the one hand, confirmed the hypothesis that the lack of continuing education interferes with professional teaching practice in the classroom; that admittedly there is a very high dropout rate among professionals from teacher education initiatives; that the majority of the research participants belong to the administrative contract of the city hall. On the other hands, they indicate that the teachers who participate in these initiatives can already see positive results mainly in relation to the acquisition of reading skills; and that the participants use in their classroom the pedagogical resources and methodologies shared with them through PNAIC.

Keywords: Continuing education. Public education. Macapá-AP.

\section{FORMACIÓN CONTINUADA DE PROFESORES DE LAS SERIES INICIALES DE LA ENSEÑANZA FUNDAMENTAL DE LA RED MUNICIPAL DE MACAPÁ-AP}

\section{RESUMEN}

La presente investigación tuvo como objetivo analizar la oferta de formación continuada a profesores de la red municipal de enseñanza de Macapá, así como av eriguar la real aplicabilidad de metodologías y recursos deriv ados de Programas y Proyectos, a la realidad de aula. Para ello, se utilizó la investigación exploratoria de campo, a partir de la cual se oyeron primero coordinadores de formaciones, que presentaron documentos y registros que confirmaron la oferta de formación continuada a los profesores de la red. A continuación, se aplicó un cuestionario que contenía cuestiones de múltiples opciones y otras disertivas, a los docentes de la red municipal que se encontraban en formación del Pacto Nacional por la Alfabetización en la Edad Cuna - PNAIC. Los resultados confirmaron la hipótesis de que la falta de formación continuada interfiere en la práctica profesional docente en el aula, que reconocidamente hay un índice muy alto de desistimiento de los profesionales en las formaciones, que los participantes de la investigación en su mayoría pertenecen al contrato administrativo del ayuntamiento, y los profesores que participan en las formaciones ya logran visualizar resultados positivos principalmente en relación a la lectura, que ellos utilizan los recursos pedagógicos y metodologías en la práctica en el aula.

Palabras clave: Formación continua. Educación pública. Macapá-AP.

\section{INTRODUÇÃO}

Asseguradas na Lei de Diretrizes e Bases da Educação Nacional LDBEN, no Plano Nacional de Educação - PNE e demais documentos que 
norteiam a educação nacional, as políticas de formação continuada de professores buscam sempre na teoria, valorizar o papel do professor, assegurando mais qualidade ao ensino, a partir do uso das mesmas metodologias e recursos pedagógicos que devem ser adotadas na prática em sala de aula por professores de todo o Brasil.

Sabe-se, porém, que devido ao grande espaço geográfico do país, das diferentes culturas e realidades existentes, nem sempre uma proposta de ensino que é executada com sucesso em uma região, é possível de ser realizada, assegurando os mesmos result ados em outras localidades. Por isso, é importante que as formações continuadas ofertadas, a partir de políticas públicas, sejam analisadas no sentido de averiguar sua real aplicabilidade em cada região para que, se necessário, sejam feitas adequações para atender às realidades dos docentes que atuam nas mais diferentes situações de trabalho. Foi o que se propôs com esse trabalho, o qual teve como principal objetivo, analisar a oferta de formação continuada, a professores da rede municipal de ensino do município de Macapá-AP, assim, como a aplicabilidade de metodologias e recursos oriundos de programas e projetos de formação continuada pelos professores em sala de aula.

O problema que levou à pesquisa foi gerado a partir da observação de que é alto o índice de desistência de professores em cursos de formação continuada que são ofertados gratuitamente pela rede de ensino municipal de Macapá, e que não há aumento considerável em relação aos resultados de avaliações de aprendizagem nacionais no que tange a alfabetização de crianças.

Para se chegar a esse conhecimento, a pesquisa selecionada, no que tange aos objetivos, foi a exploratória de campo e, com relação a abordagem, predominantemente qualitativa, com algumas características quantitativas, principalmente, na análise dos dados que foi feita utilizando-se o Discurso do Sujeito Coletivo - DSC, uma vez que foi feito um resgate da representação que as formações continuadas têm à vida dos profissionais entrevistados. 
No trabalho, aborda-se o tema da formação continuada de docentes e, especificamente, a política de formação continuada dos professores adotada pela rede municipal de ensino de Macapá, destacando-se os cursos ofertados com mais frequência, tempo de atividade, quantitativo de participantes por ano e público alvo, informações que foram prestadas pelos próprios coordenadores dos projetos e programas de formação continuada de professores no município.

$\mathrm{Na}$ seção seguinte, denominada de "Percepções e ações dos professores sobre os cursos e formação continuada oferecidos pela rede municipal de ensino de Macapá", apresenta-se a metodologia utilizada no trabalho, a caracterização e delimitação dos sujeitos da pesquisa. São delineados os aspectos éticos e legais e, também, apresentadas as análises dos dados obtidos a partir da aplicação do questionário.

As considerações sobre o trabalho realizado são apresentadas na sequência, sendo fundamentadas nos estudos bibliográficos efetuados, nas informações prestadas pelos técnicos da Secretaria Municipal de Educação - SEMED e nos dados obtidos a partir dos questionários aplicados aos professores.

\section{A POLÍTICA DE FORMAÇÃO CONTINUADA DOS PROFESSORES DA REDE MUNICIPAL DE ENSINO DE MACAPÁ}

A política de formação continuada na rede municipal de ensino de Macapá atende as prerrogativas da LDBEN e do Plano Municipal de Educação - PME desde 2015, quando aprovada a Lei no 2.178/2015-PMM, que aborda a formação continuada dos professores nas Metas 13, 14 e 16. Essas são voltadas, especificamente, aos professores do $1^{\circ}$ ao $5^{\circ}$ ano, tendo em vista que é esse público que compõe a rede de ensino.

Desses professores, os que atuam no I ciclo ( $1^{\circ}$ ao $3^{\circ}$ ano $)$ são os que mais recebem formações, pois é atribuída a eles, a função de alfabetizar os alunos, porém, essa a tarefa foi concebida durante muito tempo como responsável pela mera aquisição do código escrito pelo aluno, preparandoo para as fases seguintes. 
No entanto, a alfabetização é a que serve de base para as demais, devendo ir muito além do simples ato de decodificar símbolos. Deve-se, por meio da alfabetização, criar condições para o aluno pensar, raciocinar, buscar soluções para os problemas, fazer hipóteses, opinar, expor suas opiniões, tornar-se um sujeito crítico e participativo socialmente. Isso exige, conforme argumentado por Lima (2006, p.32), que o professor "renove sua prática pedagógica a favor de um ensino de melhor eficiência, que resultará na transformação de sua ação docente".

\subsection{Ações, projetos e atividades desenvolvidas na rede pública municipal no período de 2012 a 2017}

No quadro a seguir, apresenta-se um resumo dos principais e mais efetivos cursos de formações continuada ofertadas pela SEMED aos professores da rede municipal de Ensino de Macapá.

Quadro 1: Cursos de formação continuada comumente ofertados aos professores pela SEMED

\begin{tabular}{|c|c|c|c|c|}
\hline Cursos & $\begin{array}{c}\mathbf{N}^{\circ} \text { de professores } \\
\text { atendidos }\end{array}$ & Local do curso & $\begin{array}{c}\text { Data de } \\
\text { início }\end{array}$ & $\begin{array}{c}\text { Situaçã } \\
\text { o atual }\end{array}$ \\
\hline Lousa digital & 680 & NTM & 2016 & Ativo \\
\hline PNAIC & 750 & UNIFAP/Escola & 2013 & Ativo \\
\hline Trilhas & 750 & SESC & 2012 & Ativo \\
\hline $\begin{array}{c}\text { Batuque e } \\
\text { Marabaixo }\end{array}$ & 668 & Escolas & 2016 & Ativo \\
\hline Escolas de Leitores & 800 & Escolas & $2014 / 2015$ & Ativo \\
\hline Vaga Lume & 150 & $\begin{array}{c}\text { Escolas do } \\
\text { campo }\end{array}$ & 2008 & Ativo \\
\hline OLP & 50 & Escolas & 2008 & Ativo \\
\hline
\end{tabular}

Fonte: Elaborado pelos pesquisadores (2017).

Um projeto que apresenta especial destaque entre as formações continuadas, ofertadas pela rede municipal de ensino de Macapá aos professores, é o Escola de Leitores que foi elaborado pela própria SEMED e passou a ser executado, a partir do ano de 2014, trazendo inovações frente aos demais projetos de incentivo à leitura, exatamente, porque extrapola os muros da escola e leva a leitura a lugares, nos quais, costumeiramente, não é observada a presença de livros, sendo essa sua principal característica, e a que mais chama a atenção dos leitores. 
Além das formações voltadas aos professores, o Escola de Leitores disponibiliza às escolas, acervo literário, estantes e sacolas para emprestar livros, às crianças interessadas em fazer a leitura em casa junto com a família, amigos. Ou seja, há uma preocupação em envolver, não somente, o aluno no gosto pela leitura, mas também, outros sujeitos no processo de ensino e aprendizagem como a família que é de fundamental importância e que muitas vezes ausenta-se de sua função de educar.

Figura 1: Projeto Escola de Leitores

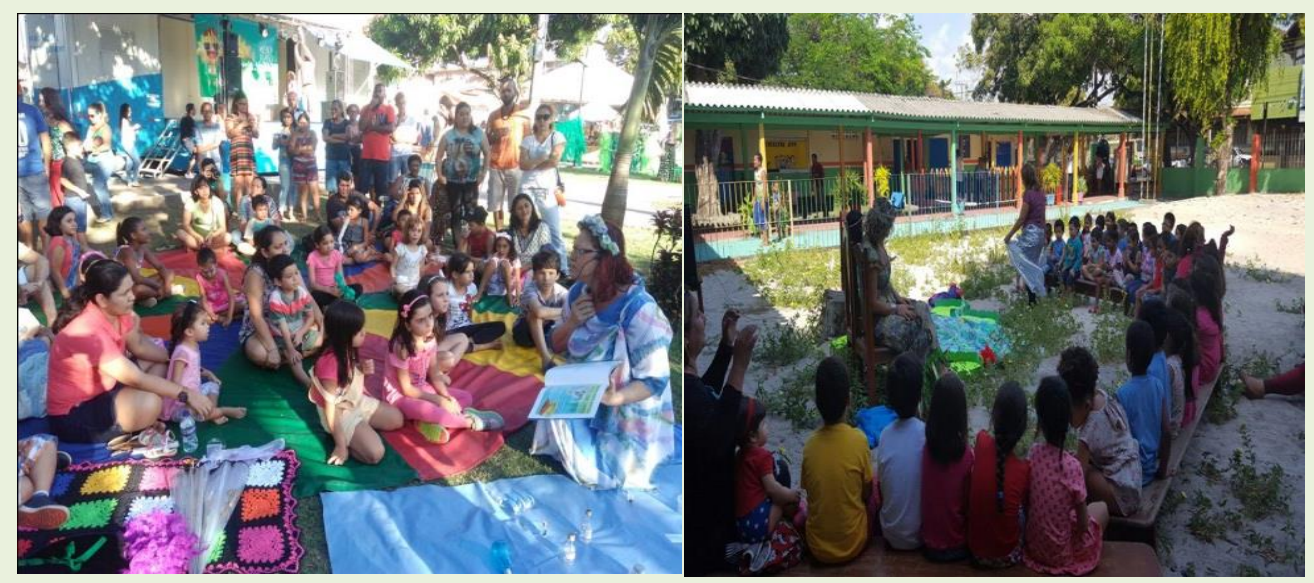

Fonte: Acervo DIRED (2017).

É possivel observar o encantamento das crianças nos registros das atividades. Isso é muito importante porque demonstra que os executores das ações do projeto, tem conhecimento de técnicas para promover a leitura entre os pequenos, confirmando-se o exposto por Villardi (1999, p. 23), ao afirmar que: "Tudo começa quando a criança fica fascinada com as coisas maravilhosas que moram dentro do livro".

Há, ainda, as formações continuadas do Pacto Nacional pela Alfabetização na Idade Certa - PNAIC, que também incentivam a prática da leitura com os alunos. As formações ocorrem anualmente desde o ano de 2013, envolvendo as áreas de linguagem e suas tecnologias, matemática e interdisciplinaridade e também aspectos da Base Nacional Comum Curricular - BNCC - Direitos de aprendizagem.

As atividades são desenvolvidas a partir do uso de atividades lúdicas e envolvem jogos tanto os enviados pelo Ministério da Educação - MEC, 
quanto os produzidos em oficinas durante a execução das formações, assim como, o uso efetivo da literatura. Esse projeto atinge a cada ano, um número maior de professores e alunos, conforme se observa no quadro 2 a seguir:

Quadro 2: Demanda de professores formados pelo PNAIC 2013 - 2017 e alunos atendidos

\begin{tabular}{|c|c|c|c|}
\hline \multirow{4}{*}{ FORMAÇÃO PNAIC } & ANO & PROFESSORES & ALUNOS \\
\cline { 2 - 4 } & 2013 & 300 & 9.000 \\
\cline { 2 - 4 } & 2014 & 400 & 12.000 \\
\cline { 2 - 4 } & 2015 & 500 & 15.000 \\
\cline { 2 - 4 } & 2016 & 650 & 19.500 \\
\cline { 2 - 4 } & 2017 & 750 & 21.500 \\
\hline
\end{tabular}

Fonte: Coordenação local PNAIC Macapá (2017).

Observa-se, de acordo com os dados, que há um aumento de 100 professores nos três primeiros anos e 150 nos dois últimos anos nas formações; sendo que esse crescimento indica uma tendência de demanda de alunos das áreas urbanas, do campo e quilombolas.

Por ser um Programa de grande porte e que recebe incentivos federais, há uma preocupação da SEMED, em assegurar que todos os professores que atuam no I ciclo participem das formações. Para o ano de 2017, estavam previstos três encontros pedagógicos, sendo que estes ocorreram nos seguintes meses, o primeiro aconteceu no mês de outubro; o segundo, em novembro e o terceiro, em dezembro. As formações ocorreram de acordo com o previsto no cronograma da SEMED, na escola municipal de educação fundamental Aracy Nascimento e escola municipal de educação infantil Meu Pé de Laranja Lima, onde se encontravam as turmas de professores da Educação Infantil.

Sobre a participação dos professores da Educação Infantil nas formações do PNAIC 2017, a coordenadora informou que praticamente $100 \%$ dos inscritos participaram com efetividade dos três encontros de estudos. Isso, de acordo com a informante, ocorreu porque, além do interesse que esses profissionais sempre demonstraram ter pelo curso, esse público dificilmente é contemplado com formações continuadas. 


\section{PERCEPÇÕES E AÇÕES dOS PROFESSORES SOBRE OS CURSOS E FORMAÇÃO CONTINUADA OFERECIDOS PELA REDE MUNICIPAL DE ENSINO DE MACAPÁ}

Quanto ao tipo de pesquisa, com relação aos objetivos, a utilizada no trabalho é classificada como exploratória de campo. Sendo que a abordagem, é caracterizada predominantemente como qualitativa, apresentando características quantitativas, por exemplo, na análise dos dados, que é apresentado quantitativamente em forma de gráficos, tem-se a quantificação das informações pertinentes à formação continuada de professores no município de Macapá. Essa interatividade entre as pesquisas é defendida por Oliveira (2008), quando argumenta que a combinação promove maior nível de qualidade e validade aos resultados.

Na análise de dados, utilizou-se o Discurso do Sujeito Coletivo - DSC, proposto por Lefevre e Lefevre (2004), que busca responder a auto expressão do pensamento ou opinião coletiva, respeitando-se a dupla condição qualitativa e quantitativa destes como objeto. Neste caso, foi a compreensão das práticas de formação continuada ofertadas aos professores da rede municipal de ensino de Macapá.

Os sujeitos da pesquisa foram professores que atuam em sala de aula nos anos iniciais do Ensino Fundamental, e a aplicação dos questionários ocorreu durante o último módulo de formação do PNAIC 2017 ( 18 e 19/2012), na EMEF Aracy Nascimento, sendo que foram distribuídos 90 questionários aos professores alfabetizadores que se encontravam em formação naquele momento, mas foram devolvidos somente 26 preenchidos.

O trabalho foi desenvolvido, respeitando-se as diretrizes da Resolução $n^{\circ}$ 466, de 12 de dezembro de 2012 do Conselho Nacional de Saúde, que dispõe sobre pesquisas envolvendo seres humanos. Neste sentido, todos os participantes da pesquisa foram orientados sobre a importância e os objetivos do estudo.

Os dados são relativos as respostas de 26 professores da rede municipal de ensino de Macapá, participantes do PNAIC 2017, tendo sido aplicado o questionário durante a realização do último módulo de estudos 
do referido ano. Sendo assim, sobre o primeiro questionamento, da indicação do vínculo empregatício dos professores, obteve-se os seguintes resultados apresentados no gráfico 1.

Gráfico 1: Vínculo empregatício dos participantes da pesquisa

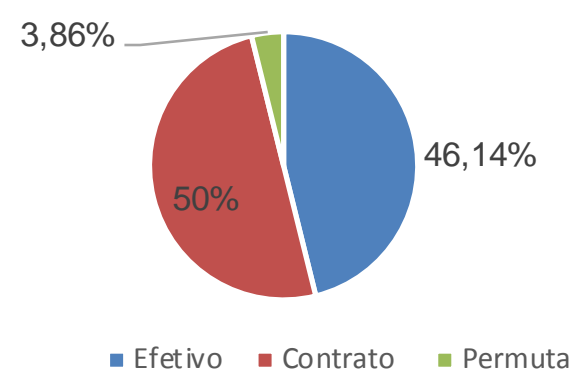

Fonte: Elaborado pelos pesquisadores a partir de dados dos questionários (2017).

Conforme se observa nos dados expressos no gráfico 1, a maioria dos professores participantes da pesquisa (50\%), pertencem ao contrato administrativo do município. Isso é um dado negativo à educação municipal, tendo em vista que há mudança constante de gestores e, consequentemente, dos contratos, ou seja, há investimentos na formação de um profissional, porém, não há garantia de que ele permaneça atuando na rede, devido às constantes mudanças oriundas, principalmente, das indicações políticas, que certamente são o cerne dos problemas educacionais no município.

O segundo questionamento efetuado aos professores, vem confirmar a constante mudança que há nos contratos a partir da indicação de tempo de atuação na rede de ensino pelos profissionais, o que é apresentado no gráfico 2.

Gráfico 2: Tempo de atuação dos professores na rede de ensino 


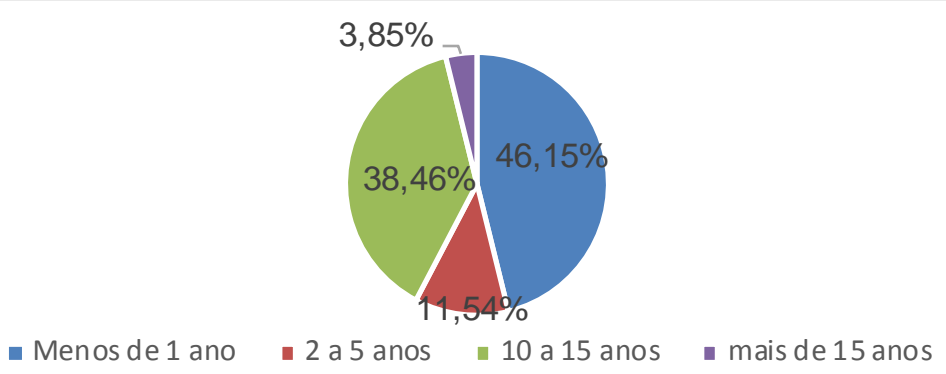

Fonte: Elaborado pelos pesquisadores a partir de dados dos questionários (2017).

Os dados apresentados no gráfico 2, confirmam a rotatividade dos professores no contrato administrativo, quando a maioria $(46,15 \%)$ afirma estar atuando na rede municipal de ensino de Macapá, há menos de 1 ano.

Conforme já mencionando anteriormente, é certo que essa mudança constante de professores, interfere diretamente nos resultados esperados com os investimentos que os governos, federal, estadual ou municipal fazem em formações continuadas, pois, o professor recebe a formação e os materiais, entretanto, não tem tempo sequer, de aplicar os conhecimentos adquiridos à sua prática em sala de aula, pois é desligado da rede.

Isso é muito preocupante, tendo em vista que a BNCC - Anos Iniciais, diminuiu o prazo para que os alunos sejam alfabetizados, ou seja, isso deve ocorrer até o $2^{\circ}$ ano do Ensino Fundamental, ou aos 7 anos de idade, o que vai exigir bem mais do professor, tendo em vista as condições que lhes são disponibilizadas para atuar em sala de aula (quantidade superior a delimitada pela LDBEN que é de 25 alunos por turma; ambiente físico inadequado; pouco material disponibilizado pelas escolas), dentre muitos outros aspectos os quais os professores são submetidos e, ainda assim, exigidos de desenvolver trabalhos que promovam resultados positivos nas avaliações nacionais de aprendizagem.

Por outro lado, quando é disponibilizado aos professores alguma condição para melhorar a sua prática cotidiana, muitas vezes, eles a desperdiçam conforme se observa nas formações do PNAIC que teve 750 professores inscritos e pouco mais da metade concluiu a formação em dezembro. Pode-se inferir então, que os conhecimentos socializados nas formações não sejam significativos aos professores, isto é, os formadores 
podem estar desenvolvendo ações que não atendem às necessidades dos alfabetizadores, que não são viáveis à prática cotidiana nas escolas.

Lima (2006) adverte que "a motivação é propulsora da aprendizagem", sendo assim, uma vez que os professores efetivos da rede municipal de ensino de Macapá ausentaram-se das formações a eles ofertadas, é provável que o único estímulo que tinham para participar era o financeiro e não o de aquisição do conhecimento, de novas metodologias e recursos para melhorar a qualidade de ensino ofertado que seria 0 esperado.

É importante que haja motivação para que o professor se disponibilize a buscar novos conhecimentos, pois, se não houver, ele acaba por estagnar na formação que the deu acesso ao cargo efetivo. Desse modo, foi importante averiguar junto aos professores entrevistados, qual o grau mais elevado de escolaridade deles, os dados apresentados no gráfico 3 são relativos a esse questionamento.

Gráfico 3: Grau de escolaridade dos professores

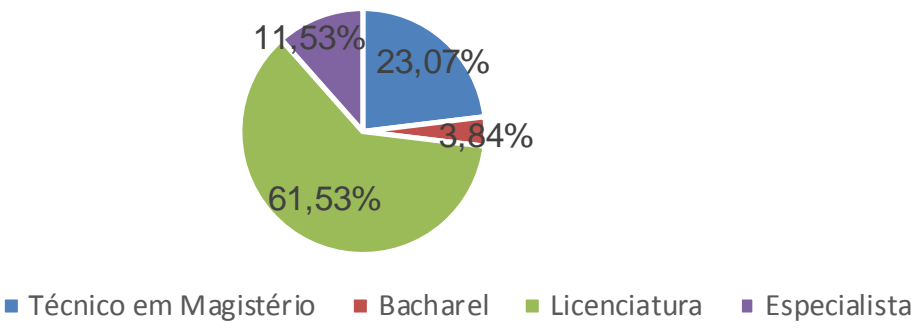

Fonte: Elaborado pelos pesquisadores a partir de dados dos questionários (2017).

Conforme se observa nos dados apresentados no gráfico 03, a maioria dos professores $(61,53 \%)$ afirma ser licenciado. Esse é um resultado bom, porque demonstra que os profissionais atendem o proposto no artigo $62 \mathrm{da}$ LDBN de que a "formação de docentes para atuar na educação básica farse-á em nível superior, em curso de licenciatura, de graduação plena [...]".

Percebe-se, porém, que o segundo maior grupo de professores que equivale a $23,07 \%$ dos entrevistados, afirma ter somente o curso técnico em magistério. Tendo sido esse resultado tão expressivo, voltou-se aos 
questionários para verificar quem eram esses profissionais e constatou-se que eles pertencem ao quadro efetivo do município e encontram-se atuando há mais de 10 anos em sala de aula.

$\mathrm{Na}$ quarta pergunta direcionada aos professores quantificou-se a periodicidade com que buscam essas formações. No gráfico 4 são apresentados os dados inerentes ao questionamento.

Gráfico 4: Frequência com que os professores participam de cursos de formação continuada

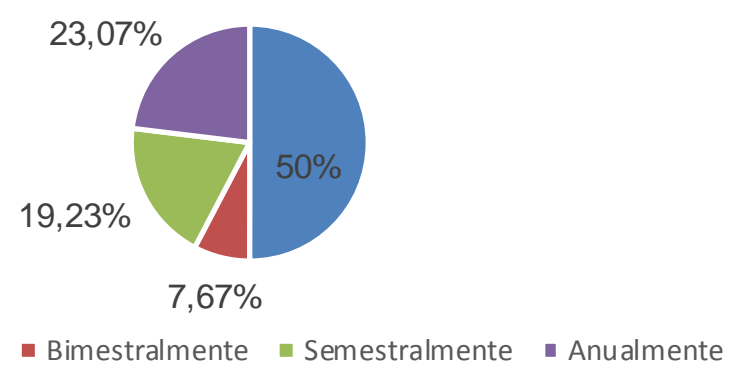

Fonte: Elaborado pelos pesquisadores a partir de dados dos questionários (2017).

Conforme os dados apresentados no gráfico 4,50\% dos professores afirmam que participam mensalmente de formações ofertadas pela SEMED, nesse caso, uma vez que todos os entrevistados encontravam-se, no ato da pesquisa, participando efetivamente da formação do PNAIC é provável que o segundo maior grupo que é de $23,07 \%$ tenha feito referência à periodicidade com que o curso é ofertado, ou seja, anualmente com formações mensais.

Independente de a formação ocorrer mensalmente, semestralmente ou anvalmente, o mais importante é a sua finalidade, ou seja, oferecer metodologias e recursos que facilitem o trabalho do professor em sala de aula, proporcionando melhores resultados ao processo de aprendizagem dos alunos, que atenda às necessidades do profissional e que sejam significativas ao seu fazer pedagógico, pois, conforme argumentado por Lima (2006), o importante é priorizar a qualidade das formações e não a quantidade. 
Desse modo, conforme se observou, a SEMED oferta vários cursos durante o ano letivo, de forma intercalada, sendo que, nenhum perdura por longos períodos. Mas será que essas formações atendem as necessidades dos professores? Foi esse questionamento que se buscou responder na questão 5 do questionário, ao perguntar o grau de satisfação dos professores para com os cursos ofertados pela SEMED. Os dados inerentes ao questionamento são apresentados no gráfico 5.

Gráfico 5: Grau de satisfação dos professores relacionado a formação continuada ofertada pela SEMED

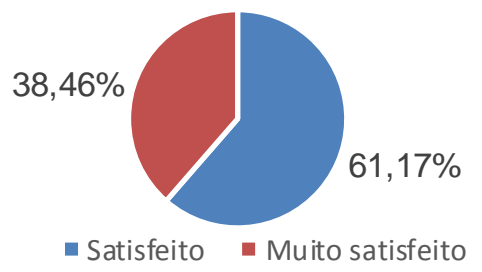

Fonte: Elaborado pelos pesquisadores a partir de dados dos questionários (2017).

Ao analisar os dados, percebe-se que a totalidade dos participantes da pesquisa afirma estar satisfeit a com as formações continuadas ofertadas pela SEMED. Esse é um resultado muito positivo, pois demonstra que as necessidades dos professores estão sendo atendidas, ao contrário do que se supôs como motivo para que os professores efetivos não participassem das formações a eles ofertadas.

Concebe-se então, que é necessário que esses profissionais sejam "resgatados" a participar efetivamente o que deve ser feito de forma a seduzir o docente para que ele possa ir em busca de novos conhecimentos que venham a renovar sua prática pedagógica. Foi a partir dessa necessidade, que se considerou importante perguntar aos professores participantes da pesquisa no questionamento 6, o que os motiva a participar de cursos de formação continuada. Os dados relativos ao questionamento são apresentados no gráfico 6.

Gráfico 6: Sobre a motivação dos professores para participar de cursos de formação continuada 
ISSN $2237-9460$

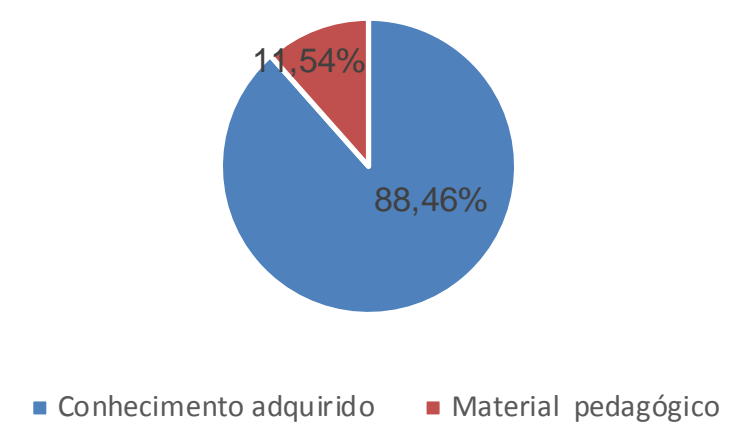

Fonte: Elaborado pelos pesquisadores a partir de dados dos questionários (2017).

Conforme se observa nos dados apresentados, a busca pelo conhecimento é considerada pela maioria dos participantes da pesquisa $(88,46 \%)$ como principal motivação para se encontrarem em uma sala de aula estudando novamente. Dentre as justificativas foram mencionados:

\footnotetext{
"Não podemos parar porque senão somos ultrapassados pelos alunos"

"É aqui nas formações que buscamos inovações para chamar a atenção dos alunos em sala de aula".

"Antes tinha a bolsa, mas para mim não fazia diferença, o que importa é o conhecimento".

"Eu gosto das metodologias utilizadas pelos formadores".

"As experiências dos colegas são muito importantes no aperfeiçoamento de minhas práticas pedagógicas em sala de aula". (DEPOIMENTOS DOS DOCENTES, 2017).
}

Isso demonstra que esses profissionais têm consciência da relevância do trabalho que desenvolvem e, conforme argumentado por Lima (2006), sabem da necessidade constante de renovar o fazer pedagógico, de buscar novas práticas, novas metodologias, que oportunizem uma troca dialógica, entre a prática e a teoria, permitindo a socialização de experiências, principalmente entre professores que at vam nos anos iniciais.

Considerando-se a necessidade de que o professor esteja sempre inovando, buscando meios de desenvolver aulas mais significativas aos alunos, perguntou-se aos entrevistados qual a importância que atribuem à formação continuada. No gráfico 7, são apresentados os dados inerentes ao questionamento.

Gráfico 7: Importância at ribuída pelos profissionais à formação continuada 

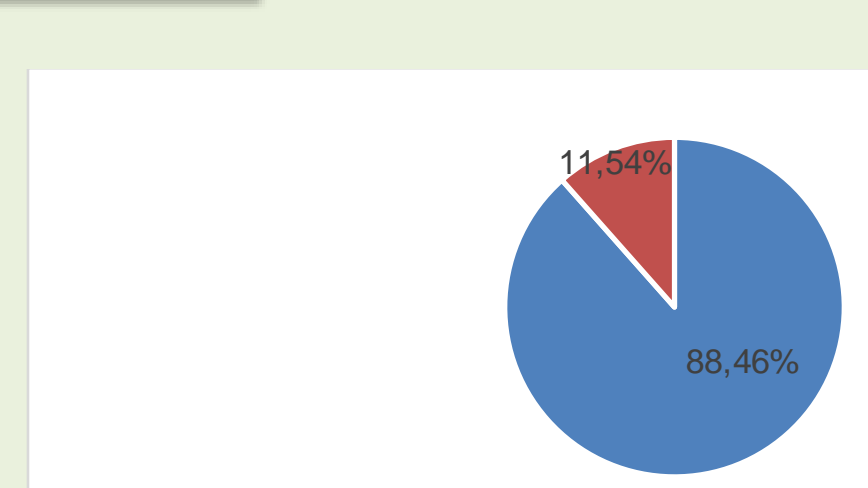

- Fundamental à prática em sala de aula

- Não respondeu

Fonte: Elaborado pelos pesquisadores a partir de dados dos questionários (2017).

Os dados demonstram que os professores participantes da pesquisa consideram a formação continuada como fundamental à prática em sala de aula (88,46\%). Há um dado que se observou repetidamente, a partir desse questionamento, o fato de que, 03 professores que equivale a 11,54\% dos participantes, não responderam a nenhuma das demais perguntas efetuadas a eles. Não se sabe o motivo, sendo assim, eles sempre aparecerão sem se posicionar nas questões seguintes.

No que tange a resposta atribuída pela maioria, não há dúvidas de que a formação continuada é fundamental à prática pedagógica, pois ela, além de possibilitar ao professor o acesso a novas metodologias e, em alguns casos recursos pedagógicos inovadores, proporciona algo fundamental a quem atua na educação, que é a reflexão sobre a prática, permitindo ao profissional, rever práticas, conceitos e, quando necessário, elaborar novas ações que priorizem principalmente a realidade do educando.

Figura 2: Momentos de reflexão e produção na formação PNAIC 2017

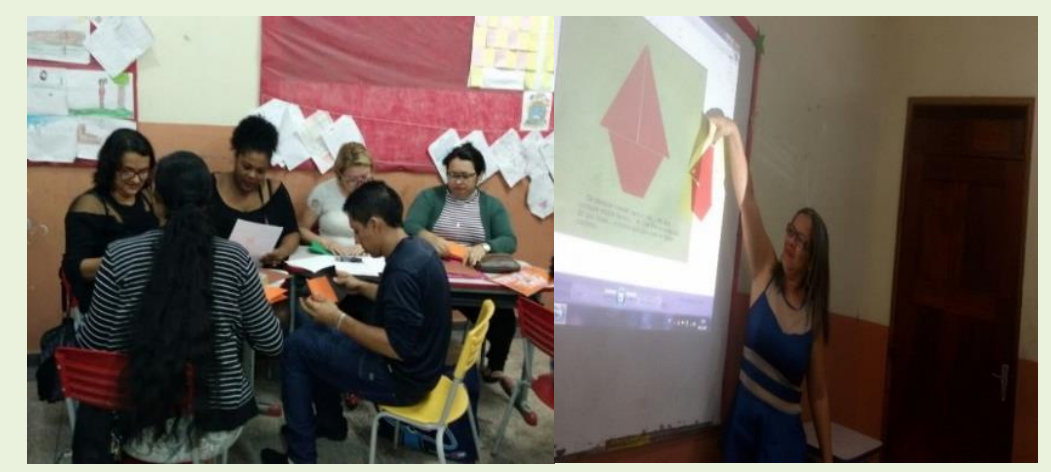

Fonte: Acervo pessoal dos pesquisadores (2017). 
É preciso salientar que, para o professor conceber os momentos de formação como condições para aprimorar seu fazer pedagógico em prol dos alunos, é preciso que conforme explicitado por Lima (2006), que o professor internalize o que aprende para depois externá-lo no seu fazer pedagógico. Logo, as condições em que os cursos são ofertados aos docentes é fundamental para que essa internalização do conhecimento ocorra, pois, se sabe que dificilmente haverá aprendizagem, se as condições físicas como o cansaço, por exemplo, interferirem no momento em que o conhecimento é socializado

Sabe-se que algumas formações, por atenderem às necessidades dos professores, são priorizadas por eles, o papel do formador, também é essencial para motivar o professor a participar das formações. Considerando-se tais aspectos, no oitavo questionamento efetuado, objetivou-se identificar se os profissionais consideram algum curso de formação continuada ofertados pela SEMED, com maior relevância à prática pedagógica em sala de aula. Os dados sobre o questionamento são apresentados no gráfico 8.

Gráfico 8: Cursos de formação continuada mais significativos aos professores

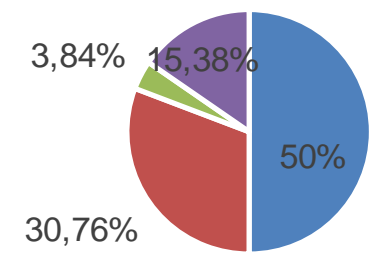

- PNAIC - Todososcursos = Curso de Educador Infantil = Não respondeu

Fonte: Elaborado pelos pesquisadores a partir de dados dos questionários (2017).

Os dados demonstram que $50 \%$ dos cursistas consideram o PNAIC como a formação continuada de maior relevância, o segundo maior grupo, que equivale a $30,76 \%$, afirma que todos os cursos são importantes à aquisição de conhecimentos para aplicar em sala de aula. 
Mas, de nada servirão os investimentos federais, estaduais ou municipais em formação continuada, se os professores, conforme referendado por Nóvoa (2002), não fizerem um investimento pessoal na própria formação, capacitando-se, por exemplo, a usar as novas tecnologias, a desenvolver trabalhos livres e criativos em sala de aula, a elaborar seus próprios planos e projetos pedagógicos, que visem tanto a construção da identidade cultural do aluno quanto a valorização das diferenças, tornando o ensino reflexivo e significativo ao aluno.

Sendo assim, perguntou-se aos professores se os cursos de formação continuada ofertados aos professores promovem condições para melhorar a qualidade do ensino ofertado. Os dados inerentes as respostas dos participantes são apresentadas no gráfico 9.

Gráfico 9: Possibilidades de melhoria à qualidade do ensino resultantes de cursos de formação continuada

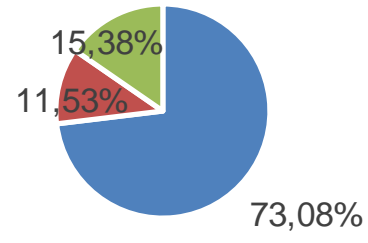

- Sim - Não Não responderam

Fonte: Elaborado pelos pesquisadores a partir de dados dos questionários (2017).

Observa-se nos dados apresentados no gráfico 9, que a maioria dos professores $(73,08 \%)$ afirma que a formação continuada thes capacita a desenvolver trabalhos de mais qualidade em sala de aula, o segundo maior grupo, optou por não responder, e três profissionais, que equivale a $11,53 \%$ dos entrevistados, considera que os cursos não promovem qualquer inovação aos trabalhos desenvolvidos em sala de aula, sendo que um profissional utilizou o seguinte argumento: "não oferece condições necessárias para atender a clientela na escola" (depoimento de professor com formação técnica em magistério, exerce a função há menos de um 
ano, contrato). Para os que consideraram que os cursos promovem mais qualidade ao ensino, obteve-se, dentre as justificativas que:

\footnotetext{
"Servem como suporte para uma aprendizagem significativa",

"Promovem a reflexão sobre o fazer pedagógico",

"Nos capacitam a utilizar as novas tecnologias",

"Consideram a realidade do educando",

"A realidade do educando é o ponto de partida para as reflexões e socializações de trabalhos em sala de aula",

"As metodologias propostas e os recursos são fundamentais para quem está atuando em sala de aula",

"Se o professor se disponibilizar a mudar, funciona".

(DEPOIMENTOS DOS DOCENTES, 2017).
}

A esse respeito, Lima (2006, p. 31) adverte: "a formação geral de qualidade dos alunos depende de formação de qualidade dos docentes". Ou seja, é necessário que o professor reflita sobre sua postura pedagógica, que se disponibilize a mudar planejamentos e ações, no sentido de tornar o ensino mais significativo ao aluno, pois, pensar em melhorias implica, conforme frisado pelos próprios professores, em "fazer algumas adaptações para o uso do material", "aprimorar o planejamento", "mudar o planejamento e a prática" (DEPOIMENTOS DE PROFESSORES, 2017).

Considerando que a maioria dos cursos ofertados pela SEMED teve início nos anos de 2012 e 2013, é provável que já possam ser visualizados melhores resultados na educação municipal. Foi para verificar se os profissionais participantes perceberam alguma mudança positiva em relação aos resultados de aprendizagem que, no décimo questionamento efetuado aos professores, perguntou-se se eles se já conseguem observar resultados positivos relacionados ao ensino da leitura, escrita e matemática, ao utilizar os recursos e metodologias propostos nos cursos de formação continuada dos quais participou. Os dados inerentes ao questionamento são apresentados no gráfico 10.

Gráfico 10: Resultados positivos relacionados ao ensino da leitura, escrita e matemática, ao utilizar os recursos e metodologias propostos nos cursos de formação continuada 


\section{ISSN $2237-9460$}

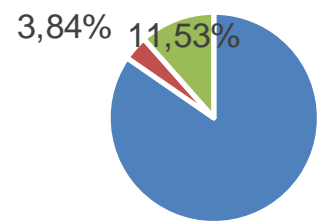

$84,62 \%$

- Sim - Não - Não responderam

Fonte: Elaborado pelos pesquisadores a partir de dados dos questionários (2017).

Os dados demonstram que a maioria $(84,62 \%)$ afirma que já é possível observar resultados positivos no ensino da leitura, escrita e matemática, decorrentes do uso de metodologias e recursos provenientes de cursos de formações continuadas. Os professores participantes da pesquisa elencaram algumas justificativas para que os avanços observados em relação à leitura, escrita e matemática ocorressem:

\footnotetext{
"Aprendemos mais maneiras de ensinar aos nossos alunos"

"Formamos alunos leitores"

"Aprendemos uma forma mais dinâmica de ensinar"

"Os cursos nos mantem atualizados"

"Os alunos ficam motivados"

"Os resultados são mais significativos"

"As crianças aprendem brincando"

"Quando temos a leitura deleite, uma quer ler mais que a outra"

"Aprimoramos o planejamento" (DEPOIMENTOS DE PROFESSORES, 2017).
}

Nesse caso, é importante referendar Castro et al (2004), ao afirmar que a criança precisa ser encantada para a leitura, o que pode ser feito pelo professor ao utilizar estratégias que tornem a ação um prazer, e não uma obrigatoriedade que é comumente observado nas escolas. Schwarzbold (2011), por sua vez, argumenta que é necessário aos alunos, conhecer os livros, no sentido de manusear, folhear, observar as imagens, as palavras, enfim, acessar a todas as informações que um livro possa oferecer.

Para isso, é necessário que a leitura seja envolvente, que cative e instigue o leitor, pois assim, ele sentirá prazer em ler, em explorar novas aventuras. Logo, há uma necessidade veemente de se apresentar os mais diferenciados gêneros textuais às crianças desde muito cedo, ainda nos 
anos iniciais de escolarização, para que se acostume a ler diferentes textos, aguçando e aprimorando o interesse pela leitura e, consequentemente, o hábito de ler.

A leitura é o "alimento da memória", pois, contribui de forma significativa para o desenvolvimento de habilidades cognitivas, assim como, torna o leitor um ser crítico, reflexivo, criativo e com competências para entender e compreender assuntos diversificados de maneira mais clara e objetiva. Nesse aspecto, percebe-se o quanto é importante o ato de ler, principalmente, no que se refere à aquisição de novas habilidades que aguçam a imaginação e a criatividade, mas para que isso aconteça de fato, a criança deve ser estimulada a ler aquilo que, inicialmente, está de acordo com o desejo dela, sendo que, o interesse desta por outros gêneros, vai se manifestando conforme as necessidades e vontades.

Sabe-se que, atualmente, o ensino no munício de Macapá passa por um processo de mudanças, apesar de paulatinas, que estão contribuindo para a ampliação de programas educacionais que contribuirão para o desenvolvimento de técnicas e metodologias no ensino e aprendizagem, o que, consequentemente, refletirá positivamente tanto no índice de Desenvolvimento da Educação Básica - IDEB como nas escolas municipais.

O fato de, já serem notados avanços nos resultados de aprendizagem dos alunos, indica que é possível melhorar a qualidade do ensino, pois, conforme argumentado por Lima (2006, p.33), a "formação continuada abre perspectivas de construir ações concretas na busca da qualificação do trabalho docente de qualidade". Desse modo, foi necessário averiguar junto aos participantes da pesquisa, no décimo primeiro questionamento, se é possível desenvolver as metodologias, assim como, utilizar adequadamente os recursos disponibilizados em cursos de formação continuada dos quais tivessem participado. Os dados relativos à pergunta são apresentados no gráfico 11.

Gráfico 11: Aplicabilidade de metodologias propostas em cursos de formação continuada em sala de aula 


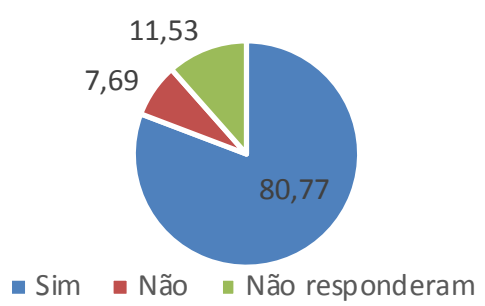

Fonte: Elaborado pelos pesquisadores a partir de dados dos questionários (2017).

Percebe-se que a maioria dos participantes da pesquisa, que representa $80,77 \%$, afirma ser possível utilizar as metodologias e recursos pedagógicos propostos nos cursos de formação continuada ofertados pela SEMED, nas atividades desenvolvidas em sala de aula. Conforme já foi referendado durante o desenvolvimento desse trabalho, são muitos os empecilhos que interferem para que o professor aplique na prática, o que aprendeu em sala de aula, no ato das formações, mas, sabe-se também, que a criatividade é uma característica docente, logo, se o professor não tem como realizar uma determinada tarefa de uma forma, é necessário que faça adequações para realizá-la de outra forma.

O docente deve estar sempre envolvido nesse processo de ensino e aprendizagem ativamente, como também, ter metodologias condizentes com a realidade de cada espaço escolar, isto é, ser um indivíduo transformador que, independentemente das condições de trabalho, seja capaz de compartilhar o conhecimento com o aluno, fazendo com que este ser se torne um cidadão crítico, reflexivo e consciente.

Por isso, Moretto $(2009$, p.24) defende a busca efetiva dos professores por novos conhecimentos, novas práticas de ensino que promovam mais qualidade aos trabalhos ofertados em sala de aula, porque, conforme argumenta, "o professor não pode ficar "preso" apenas ao que é ensinado em uma graduação", pois, se assim o fizer, ele estará desperdiçando uma gama de outros conhecimentos que são fundament ais à quem atua na área educacional, tais como, os recursos que são disponibilizados por projetos e programas federais e municipais voltados à educação.

Com o objetivo de identificar se há o recebimento e uso efetivo desses recursos pelos professores em sala de aula, se elaborou a décima segunda 
pergunta do questionário. Os dados acerca do questionamento são apresentados no gráfico 12.

Gráfico 12: Sobre o recebimento de recursos (lúdico literário) oriundo de programas e projetos que são efetivamente utilizados na rede em cursos de formação continuada

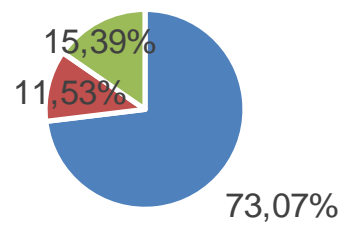

- Sim, recebeu e faz uso - Não recebeu - Não respondeu

Fonte: Elaborado pelos pesquisadores a partir de dados dos questionários (2017).

Aqui, é importante ressaltar que os três professores que negativaram a questão, equivalente a $11,53 \%$ dos participantes da pesquisa, esclareceram que é o primeiro ano que participam das formações. Conforme informado pela maioria $(73,07 \%)$, os recursos pedagógicos provenientes de projetos e programas de formação continuada foram recebidos e são utilizados com frequência em sala de aula.

Esse é um resultado que se considera positivo, pois, uma vez que o professor utiliza tais instrumentos de ensino, ele está promovendo a articulação entre as diferentes áreas do conhecimento. Ou seja, o professor pode utilizar um livro de Ciências Humanas, ou de Ciências da Natureza, por exemplo, "em atividades destinadas ao desenvolvimento de habilidades importantes à alfabetização". Os jogos, por sua vez, "são facilitadores da aprendizagem, pois, além de promoverem a interação entre as crianças, contribuem para o desenvolvimento e bem-estar no ambiente escolar" (BRASIL, 2009, p. 07).

Sabe-se, porém, que muitas vezes, a própria escola dificulta o acesso a esses matérias. Sendo assim, a pergunta que finalizou a pesquisa com os professores foi quais as maiores dificuldades encontradas por eles para utilizar as metodologias e recursos enviados por projetos e programas às escolas. Os dados inerentes ao questionamento são apresentados no gráfico 13. 
Gráfico 13: Dificuldades elencadas pelos professores para utilizar metodologias e recursos provenientes de Projetos e Programas de formação continuada em sala de aula

$30,76 \%$

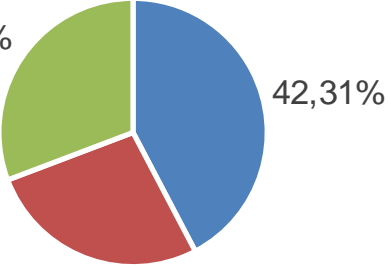

$26,92 \%$

- Acesso aos materiais " Não respondeu "Não há dificuldades

Fonte: Elaborado pelos pesquisadores a partir de dados dos questionários (2017).

Aqui, é importante fazer referência ao depoimento da coordenadora do Projeto Trilhas 3 , ao relatar que em visita de acompanhamento de uso dos recursos pelos professores no ano de 2013, encontrou as caixas lacradas, ou na secretaria das escolas, ou na sala do diretor. Foi citado por ela, o caso de uma escola cujo material (várias caixas) entregue em mãos à direção da escola pela própria coordenadora, desapareceram misteriosamente da escola, fato que só foi detectado quando foi realizada a visita de acompanhamento do uso dos materiais. Após intervenção da secretária de educação na época, o material reapareceu da mesma forma que havia sumido.

Vasconcelos; Lima e Selva (2009, p.2) ressaltam as mesmas dificuldades observadas, durante a prática de estágio realizado em escolas públicas e privadas quando detectaram que "Os jogos e os brinquedos encontravamse em armários fechados, geralmente na diretoria, ficando "indisponíveis" aos educadores". As autoras ressaltam ainda, que em outras situações "os jogos não eram utilizados pela falta de informação de como manipulá-los, como foi afirmado por alguns professores durante a nossa observação".

Os exemplos demonstram as dificuldades que os docentes encontram para utilizar os recursos que chegam às escolas. Por isso, é importante que os coordenadores pedagógicos também participem de cursos de formação continuada, destinada aos professores, pois assim, eles terão conhecimento

\footnotetext{
3 Formação continuada ofertada aos professores da rede municipal de ensino de Macapá, que também disponibiliza como recursos ao professor, obras literárias e jogos pedagógicos.
} 
dos recursos disponibilizados, das metodologias de ensino propostas, e atuarão em parceria com os professores, para fazer valer o direito ao uso dos recursos disponibilizados em sala de aula, assegurando que não ficarão trancafiados a "sete chaves", sem proporcionar qualquer tipo de melhoria ao trabalho do professor com os alunos, pois se assim acontecer, de nada adiantará investir em cursos de formação continuada e na aquisição de recursos pedagógicos.

Logo, além de ser necessário que os coordenadores pedagógicos sejam contemplados em cursos de formação continuada, destinados a professores, é imprescindível que façam o acompanhamento bem próximo das atividades realizadas em sala de aula com os alunos. Isso é importante porque, uma vez identificando as dificuldades, esses profissionais podem, em conjunto com os docentes e toda a comunidade escolar, organizar as ações, planejar estratégias de ensino que contemplem a realidade dos educandos tornando o ensino significativo ao aluno.

\section{CONSIDERAÇÕES FINAIS}

O estudo nos levou a compreensão de que a formação continuada de professores é muito importante à vida profissional docente e deve ser disponibilizada pelas instituições responsáveis pela educação, de forma efetiva, pois, é a partir das reflexões, da troca de conhecimentos proporcionadas nos estudos, do acesso à novas metodologias, às práticas de ensino inovadoras, que resultem em um processo de ensino e aprendizagem mais significativo ao aluno, que o professor vai poder prestar um trabalho de mais qualidade em sala de aula e, consequentemente, haverá avanços nos índices de avaliação nacional, que atualmente é uma das maiores preocupações dos gestores educacionais.

Com o trabalho, comprovou-se a hipótese de que a falta da formação continuada interfere na prática cotidiana docente, pois, não tendo conhecimento de novas perspectivas de ensino, de metodologias e recursos inovadores que auxiliem no processo de ensino e aprendizagem do aluno, a tendência é que as aulas não sejam motivadoras e não atendam 
aos interesses dos alunos em sala de aula, fazendo com que criem aversão à escola, diminuindo ainda mais os índices de aprendizagem.

Sabe-se que, cativar e obter a atenção da criança ao que está sendo ensinado em sala de aula, não é uma tarefa fácil, por isso, se há essa dificuldade, o que é comum se observar nas escolas, é preciso que o profissional reconheça o problema e busque soluções para resolvê-lo, pois, se as aulas não forem significativas, não chamarem a atenção do aluno, ele não irá prestar atenção e não adianta o professor impor castigos, mandar para o serviço técnico pedagógico, chamar pais, conselho tutelar, isso, além de não promover qualquer resultado positivo, irá afastar ainda mais a criança do processo de ensino e aprendizagem, dificultando ainda mais o trabalho do professor, pois, além de não ter atenção daquele aluno, terá perdido o tempo e ainda, desviado a atenção dos demais alunos.

Nesse sentido, para evitar situações conflitos gerados pela não participação do aluno nas atividades realizadas em sala de aula, o professor deve ter, além do domínio dos conteúdos a serem trabalhados, capacidade e tempo para planejar, delimitar objetivos, considerando a realidade da sala de aula em que atua, selecionar a metodologia de trabalho e os instrumentos pedagógicos a serem utilizados, de forma que as aulas tornem-se dinâmicas, participativas, que façam com que o aluno tenha vontade de participar e de interagir.

É preciso que a criança seja conquistada, que tenha vontade de estudar, que não seja forçada a ir para a escola, como um executor de tarefas, de deveres a ela impostos, que para realizá-los, não pode sair dos padrões estabelecidos pela escola e pelo professor, que seriam aqueles que Ihes dariam condições para selecionar os melhores caminhos a serem percorridos para a execução da tarefa que é adquirir conhecimentos para a vida, para mudar a realidade em que vive.

Nesse caso, a SEMED está cumprindo seu papel, ao ofertar as formações continuadas aos professores, está capacitando os profissionais, Ihes dando condições teóricas e práticas para melhorar a qualidade do ensino ofertado em sala de aula, o que foi comprovado com a pesquisa de 
campo. Comprovou-se ainda, que há uma diversidade de cursos disponibilizados aos professores, englobando várias temáticas, mas que são priorizados principalmente os de incentivo à leitura.

No entanto, os resultados demonstram que há um certo descaso dos profissionais para com as formações, o que foi constatado com a quantidade de ausentes no último módulo do PNAIC 2017, ocorrido no mês de dezembro do mesmo ano, quando quase a metade de inscritos deixaram de participar das formações e ainda, que dentre os participantes, metade são pertencentes ao contrato administrativo, o que nos leva à compreensão de que os efetivos não estão atribuindo o devido valor às formações e, consequentemente, acabam por não colaborar para melhorar a qualidade do ensino ofertado à sociedade, em escolas da rede municipal de ensino.

A pesquisa nos levou ainda, a perceber que a maioria dos professores participantes considera que a formação continuada lhes capacita a desenvolver trabalhos de mais qualidade em sala de aula, sendo suporte para o desenvolvimento de aulas mais significativas, para usar as novas tecnologias em favor da educação, permitem ao professor, refletir sobre a prática profissional e, acima de tudo, fornecem condições ao docente para adequar os conteúdos à realidade dos alunos, considerando os conhecimentos prévios, a cultura, dentre outros aspectos. Há, no entanto, quem discorde, afirmando que os estudos não thes fornecem condições para aplicar as metodologias e recursos à prática em sala de aula, o que é uma parcela bem pequena dos entrevistados.

Mesmo sendo notórios os avanços na qualidade da educação do município de Macapá, a partir da efetivação da oferta de formação continuada aos professores, sabe-se que ainda há muito que melhorar, principalmente, no que tange à participação dos professores nos cursos a eles ofertados. Por isso, é necessário que a SEMED elabore estratégias que viabilizem a participação do professor nas formações, como por exemplo, destinar um dia do calendário letivo, para que ocorram as formações mensais, pois, uma vez que cada módulo tem carga horária prevista de 
8h/a, ela pode ocorrer em apenas um dia (manhã e tarde), sem exigir a sobrecarga de trabalho do professor, que, na maioria das vezes, desenvolve suas funções em sala de aula, nos dois turnos e a noite, cansado, já não tem motivação para estudar. Esse dia pode ser contabilizado como letivo, tendo em vista que o professor está estudando para melhorar a qualidade do ensino.

A prova de que se for destinado um dia para os profissionais participarem das formações é o caminho certo para diminuir o índice de desistência de professores nos cursos de formação continuada, são os docentes de escolas do campo, que contabilizaram mais de $80 \%$ de presença no encontros realizados em 2017, ainda que tenham tido que se deslocar de localidades distantes, como os do Distrito do Bailique no Amapá, por exemplo, que enfrent am mais de quatro horas de viagem de barco para chegar aos locais de formação que ocorrem na capital Macapá. Considerase que essa é uma proposta viável tendo em vista que os conhecimentos adquiridos pelos professores vão levar benefícios aos trabalhos desenvolvidos na prática cotidiana e mais qualidade ao ensino ofertado ao aluno que é o personagem principal do processo educacional.

Outra possibilidade de assegurar a permanência dos professores nas formações é com a elaboração de documento que torne a obrigatoriedade da participação de professores efetivos nas formações. Pois, uma vez que o profissional ganha 40 horas e exerce a função em apenas um turno ${ }^{4}$, e ainda, que ganha dedicação exclusiva e gratificação de alfabetização, (caso dos efetivos que sempre atuam no ciclo de alfabetização), e que as formações são gratuitas e voltadas a elevar a qualidade do ensino, não é considerado nenhuma infração, e nem uma decisão abusiva, tornar obrigatória a participação dos professores, pois a formação continuada está prevista também no Plano Municipal de Educação.

Os profissionais por sua vez, devem sair da acomodação e buscar novos conhecimentos, que lhes possibilitem melhorar o fazer pedagógico em

\footnotetext{
4 Somente em caso de pró-labore é que o professor retorna no segundo turno.
} 
sala de aula, desenvolvendo aulas mais dinâmicas, participativas e significativas aos alunos, pois, devido à desleal concorrência entre as tecnologias que são acessiv eis aos alunos fora e dentro do ambiente escolar, e os recursos que a escola comumente disponibiliza aos profissionais para o trabalho em sala de aula, se o professor não inovar, não buscar meios de envolver o aluno para que ele interaja, participe das aulas, ele não vai prestar atenção ao que é ensinado e consequentemente não haverá a aprendizagem.

Vale salientar, que o aluno só vai ser aprovado ao final do terceiro ano se ele for capaz de ler e escrever, ressaltando que essa capacidade ultrapassa $o$ ato de codificar e decodificar signos escritos, exigindo que o aluno seja capaz de ler gêneros textuais diversificados, contextualize as informações presentes no texto e compreenda a mensagem que está sendo veiculada. Conforme foi frisado ao longo desse trabalho, essa não é uma tarefa fácil de ser alcançada em três anos de ensino, considerando-se a realidade das escolas da rede municipal de Macapá.

Por isso, já que a SEMED oferta os cursos de formação continuada, englobando diferentes temáticas aos professores, no sentido de melhorar a qualidade do ensino, é preciso que seja assegurada a efetiva participação dos profissionais nas formações, pois de nada adianta investir em melhorias, se quem atua diretamente com os alunos, não se empenhar em participar das formações.

Ao finalizar esse trabalho, a visão que se tem é que no período de 2012 a 2017, o investimento da SEMED na formação de professores já apresenta resultados positivos, que podem ser visualizados em escolas como a Maria Luiza Bello, que representou o estado do Amapá em seminário em São Paulo, sobre alfabetização, por ter alcançado o índice mais elevado do estado do Amapá, no eixo leitura, no IDEB de 2016. Da Escola Goiás, que já atingiu a meta estipulada para 2020, do empenho dos professores do campo, que se deslocam de regiões distantes, porque sabem que a formação continuada, a busca por conhecimentos é fundamental a prática em sala de aula. 
Os exemplos citados são ínfimos diante dos benefícios que 0 conhecimento adquirido pode oferecer aos professores e alunos no processo educativo. Por isso, é necessário que a oferta de formações continuadas aos professores, continue sendo uma ação constante e priorizada pela SEMED, pois esse é o caminho mais fácil para melhorar a qualidade da educação.

Que nas formações continuadas futuras, os profissionais da Educação Infantil recebam a mesma atenção que os do Ensino Fundamental, pois assim, a SEMED estará assegurando uma base sólida de formação, que será refletida nos anos subsequentes de ensino, com melhores resultados na aprendizagem dos alunos, e nas avaliações nacionais que representa a maior preocupação dos gestores públicos em educação, fazer com que a educação do município ou do estado, figure entre os melhores resultados do país.

\section{REFERÊNCIAS}

BRASIL. Ministério da Educação. Documento orientador do Pacto Nacional pela Alfabetização na Idade Certa - PNAIC, Brasília, DF, 2017.

BRASIL. Ministério da Educação. Conselho Nacional de Saúde. Resolução nº 466, de 12 de dezembro de 2012. Brasília, DF,2012.

BRASIL. Ministério da Educação. Decreto $n^{\circ} 5.622$, de 19 de dezembro de 2005. Regulamenta o art. 80 da Lei n o 9.394, de 20 de dezembro de 1996, que estabelece as diretrizes e bases da educação nacional. Brasília, DF,2005.

BRASIL. Lei No 10.639, de 9 de ianeiro de 2003. Altera a Lei no9.394 de 20 de dezembro de 1996, que estabelece as diretrizes e bases da educação nacional, para incluir no currículo oficial da Rede de Ensino a obriaatoriedade da temática "História e Cultura Afro-Brasileira", e dá outras providências. Brasília, DF,2003.

BRASIL. Lei de Diretrizes e Bases da Educação Nacional, n 9394, de 20 de dezembro de 1996. Brasília, DF,1996.

CASTRO, P. C. V. de; SOUSA, A. C. de; SOUZA, R. J. de; SOUZA, G. C. de. Leitura do professor, leitura do aluno: processos de formação continuada, 2004. Disponível em:

<www.unesp.br/proarad/PDFNE2004/artigos/eixo3/leituraprofessor.pdf>. Acesso em: 23 mar. 2017.

LEFEVRE, F.; LEFEVRE, A. M. C. Discurso do sujeito coletivo: representações sociais e intervenções comunicativas. In: Texto Contexto Enferm, Florianópolis, 
2004 Abr-Jun; 23(2): p. 502-507. Disponível em:

http://www.scielo.br/pdf/tce/v23n2/pt_0104-0707-tce-23-02-00502.pdf.

A cesso em: 08 dez. 2017.

LIMA, R. de S. Formação continuada e a prática docente de professores dos anos iniciais do Ensino Fundamental de escolas particulares de Porto Alegre. Pontifícia Universidade Católica do Rio Grande do Sul. Porto Alegre. Março de 2006.

MACAPÁ. Prefeitura Municipal de. Projeto de Lei $\mathbf{n}^{\circ} \mathbf{2 . 1 7 8 / 2 0 1 5 - P M M . ~ A p r o v a ~}$ o Plano Municipal de Educação, de Macapá (PME/MCP) e dá outras providências. Macapá, AP, 2015.

MORETTO, V. P. Prova: Um momento privilegiado de estudo, não um acerto de contas. 8. ed. São Paulo, SP: Lamparina, 2009.

NÓVOA, A. Os professores e a sua formação. Lisboa Dom Quixote, 2002.

OLIVEIRA, M. M. de. Como fazer pesquisa qualitativa. Petrópolis-RJ: Vozes, 2008.

SCHWARZBOLD, C. Desenvolver a competência leitora: desafio ao professor do ensino fundamental, Pelotas: UFP, 2011.58 p. Monografia - Pós-

Graduação em Linguística Aplicada. Disponível em:

<http://wp.ufpel.edu.br/letras-pos/especializacao/files/2012/02/Desenvolvera-compet\%C3\%AA ncia-leitora-desafio-ao-professor.pdf.>. Acesso em: 03 set. 2017.

VASCONCELOS, D. O. V. de; LIMA, E. A. P.; SELVA, A. C. V. S. Jogos e brincadeiras: uma necessidade infantil. 2009. Disponível em:http://www.fundaj.gov.br/geral/educacao_foco/dayane\%20e\%20edlan e.pdf. Acesso em: 17 set. 2017.

VILLARDI, R. Ensinando a gostar de ler e formando leitores para a vida inteira. Rio de Janeiro: Qualitymark, 1999.

Recebido em: 25 de agosto de 2018. Aprovado em: 10 de abril de 2019. 